\title{
THE ASSOCIATION BETWEEN RURALITY AND RETURN TO WORK FOR WORKERS' COMPENSATION CLAIMANTS WITH WORK-RELATED MUSCULOSKELETAL INJURIES: AN ANALYSIS OF WORKERS WHO FAILED TO RETURN TO WORK WITHIN TYPICAL HEALING TIME FRAMES
}

\author{
University of Alberta, Edmonton, Canada \\ ${ }^{1}$ Faculty of Rehabilitation Medicine \\ ${ }^{2}$ School of Public Health \\ ${ }^{3}$ Department of Medicine \\ ${ }^{4}$ Department of Physical Therapy
}

CALLUM A. LAVOIE ${ }^{1}$, DON VOAKLANDER ${ }^{2}$, JEREMY R. BEACH ${ }^{3}$, and DOUGLAS P. GROSS ${ }^{4}$

\begin{abstract}
Objectives: The objectives of this study have been to: 1) describe and compare urban and rural injured worker populations in Alberta, Canada; 2) identify return-to-work outcomes in urban and rural populations; 3) examine the relationship between geographic location of residence and recovery from work-related musculoskeletal injury; and 4) investigate if this relationship is attenuated after controlling for other known risk factors. Material and Methods: This study was a secondary analysis utilizing data of a population of musculoskeletal injury claimants who underwent clinical/RTW (return to work) assessment between December 2009 and January 2011 collected by the Workers' Compensation Board of Alberta. Descriptive statistics were computed for 32 variables and used for comparing urban and rural workers. The logistic regression analysis was performed to test the association between geographic location of residence and likelihood of return-to-work. Results: Data on 7843 claimants was included, $70.1 \%$ of them being urban and $29.9 \%$ - rural. Rural claimants tended to have spent less time in formal education, have a blue-collar job, have no modified work available, have a diagnosed comorbidity, and not been enrolled in a specialized rehabilitation program. They were $1.43(1.12-1.84)$ times the odds more likely than urban claimants to be continuing to receive full disability benefits 90 days after their RTW assessment, and 1.68 (1.06-2.67) times the odds as likely to report a recurrence of receiving disability benefits. Conclusions: Rural residence was associated with prolonged work disability, even after controlling for age, job type, education level, health utilization and other potential confounders. Further research is required to explore why injured workers in rural settings experience prolonged reception of disability benefits and have greater rates of recurrence of receiving disability benefits. Int J Occup Med Environ Health 2017;30(5):715-729
\end{abstract}

Key words:

Occupational injury, Musculoskeletal, Return to work, Rural, Urban, Workers' Compensation Board Injury Claimants

Received: February 10, 2016. Accepted: July 25, 2016.

Corresponding author: C.A. Lavoie, University of Alberta, Faculty of Rehabilitation Medicine, 3-62 Corbett Hall, Edmonton, T6G 2G4 Alberta, Canada (e-mail: callum1@ualberta.ca). 


\section{INTRODUCTION}

Workplace musculoskeletal (MSK) injuries pose serious, health, occupational, and socio-economic risks. Globally, they are a leading cause of worker disability alongside cardiovascular disease and cancer [1,2]. In 2007 the economic burden of occupational injuries in the United States was estimated to be 6 billion dollars for 5600 fatal injuries and 186 billion dollars for 8599000 nonfatal injuries [1]. Likewise, while not all occupational injuries result in financial compensation for the worker, in 2003 it was assessed that 630000 Canadians experienced an occupational injury resulting in some limitation of activity [3].

Furthermore, the Canadian Community Health Survey concluded that 4.27 million Canadians over 12 years of age, or $15 \%$ of the population, suffered an injury severe enough to limit their normal activity in 2009-2010 [4]. In 2012, workplace injuries in Alberta, Canada, totaled over 1.3 billion dollars in injury claim costs for disability [5]. In 2011, workplace injuries in Alberta accounted for 50622 disability claims, over 607000 workdays lost, a lost-time claim rate of 1.49 per 100 workers, and a disability claim (lost time or requiring modified work) rate of 2.82 per 100 workers [6]. In 2012, the Workers' Compensation Board (WCB) of Alberta had 27745 accepted time-loss injury claims and Canada as a whole had 245365 claims [7].

Return to work (RTW) is a primary outcome measure used by most insurers of workplace injury, such as workers' compensation boards [8]. Serving as a surrogate measure of physical, psychological, social, and economic recovery for both the individual and the population, research has shown RTW to be positively associated with improved health-related quality of life [9]. While the majority of workers who suffer an occupational MSK injury return to work relatively quickly and without complication, there remains a subset that fails to do so and often undergo further assessment and rehabilitation.

Many risk factors for unsuccessful RTW post-MSK injury have been described, including biophysical factors such as older age [8,10-12], greater pain, disability, and severity of injury [12-15], poorer health [12], being a smoker [10], less interdisciplinary rehabilitation [16-18], and psychosocial factors such as blue-collar employment [3,8,19-22], lower education level [10,13-15,23], lower income [21,24], and psychological factors including lower self-efficacy or greater levels of depression $[10,13,16]$.

While there is limited research investigating the association of rural residence with RTW, this factor is especially relevant to countries such as Canada and the USA with strong rural heritages. In the 2011 Canadian census, 19.4\% of the Albertan population was defined as residing in a rural area or small town [25]. An investigation in the state of Washington showed that rural and small town claimants were on longterm disability for a greater period of time [26], and rural North Carolina residents receiving treatment for chronic low back pain had greater functional loss when compared to their urban counterparts [27]. Conversely, the research across multiple states in the USA by Young et al. concluded that injury claimants from rural and less densely populated areas experienced shorter durations of work disability when compared to their urban counterparts [28].

In Canada specifically, census data has identified rural populations as having several risk factors for delayed RTW. This includes having an older average age, having lower socio-economic status, being less well educated, and having poorer health [10,29,30]. However, while there is a thorough understanding of the association between many demographic, occupational, and health factors and RTW from MSK injury in the population as a whole, there remains insufficient research investigating both how the distribution of these factors differs in urban and rural populations, and to what degree rates of RTW differ between these 2 populations, if at all. Furthermore, as no research focusing on this question has been performed in Canada, and research from other regions has limited generalizability, further investigation could provide insight on a relevant and under-researched topic. 
Thus, the study objectives have been to:

1. Describe and compare urban and rural injured worker populations in Alberta, Canada.

2. Identify return-to-work outcomes in urban and rural populations.

3. Examine the relationship between geographic location of residence and recovery from work-related musculoskeletal injury.

4. Investigate if this relationship is attenuated after controlling for other known risk factors.

\section{MATERIAL AND METHODS}

\section{Design}

This was a secondary analysis of a cohort study conducted previously, which had been described in detail elsewhere [31]. The study used administrative data from WCBAlberta. Health care professionals treating WCB-Alberta claimants collected the information for the purposes of administrative records, patient care, and program evaluation/research. Data from across the province was systematically collected at the time of clinical assessment for determining readiness to return to work [32,33]. These claimant records had been used previously for investigating population health and rehabilitation from workplace MSK injuries [31,34]. This study was approved by the University of Alberta's Health Research Ethics Board.

\section{Subjects}

The study population consisted of WCB-Alberta claimants with sub-acute or chronic MSK injuries who underwent clinical assessment to determine readiness to RTW between December 2009 and January 2011. They were drawn from a population of residents of Alberta who experienced a workplace MSK injury, filed a compensation claim, and failed to return to regular duties or had ongoing difficulties at their place of employment beyond what was expected as a typical healing timeframe. Thus, the injured workers in this data set are not representative of all injured workers in Alberta, but instead represent a subset of the injured worker population. Further detail on the assessment process as part of a continuum of care is available elsewhere [35].

Inclusion criteria for this study were: a) Alberta residents, b) open WCB claim for MSK injury, and c) first admission to RTW assessment. Exclusion criteria were: a) surgery pending at the time of assessment, b) head injury, c) traumatic psychological injury, or d) further medical investigation recommended after the assessment. After applying inclusion and exclusion criteria, data on 7843 from a total of 9389 claimants remained was analyzed for the purposes of this study.

\section{Variables}

The primary variable of interest in this study was geographic location of residence. Workplace musculoskeletal injury claimants from communities with a population > 50000 people were categorized as urban, or metropolitan, while MSK injury claimants from communities with populations $<50000$ people were categorized as rural, or non-metropolitan. A population of $50000 \mathrm{had}$ been used previously in the research in Alberta as a cutoff for urban and rural populations [36].

A total of 31 other descriptive variables were included in this study. These were categorized into demographic (e.g., age, sex, level of education), occupational (e.g., preinjury annual earnings, type of work, modified work availability, reception of wage replacement benefits) and health factors (e.g., diagnosis group of injury, co-morbidities, rehabilitation program, number of doctor visits). Patientreported health outcome measures were also included in the form of the Pain Visual Analog Scale (VAS), the Pain Disability Index (PDI), and the Short Form 36 Health Survey (SF-36).

We created the 'type of work' variable by sub-classifying the National Occupational Classification's (NOC) employment sectors into white-collar, blue-collar, and health 
care field jobs [37]. The NOC is a Canadian governmentdesigned tool used for categorizing occupations in accordance to standardized and consistent criteria. The ten broad occupational classifications in NOC are: management (1); business, finance, and administration (2); natural and applied sciences and related occupations (3); health (4); education, law, and social, community, and government services (5); art, culture, recreation, and sport (6); sales and service (7); trades, transport and equipment operators and related occupations (8); natural resources, agriculture, and related production occupations (9); manufacturing and utilities (10) [37].

These 10 categories were sub-categorized into 3 groups for this project as white-collar, blue-collar and health care. White-collar work was identified as categories 1, 2, 4, 5, 6, and 7. Blue-collar work was identified as categories 8, 9, and 10. Employment in the Health Care field was identified as category 3. Jobs in the health field were analyzed separately because they comprised a large portion of the jobs and tend to have characteristics of both blue and white-collar employment.

Outcome variables - in order to most thoroughly describe and compare the urban and rural populations, multiple measures were investigated. This is because the definition of what constitutes successful RTW for a claimant may vary. Multiple analyses were performed utilizing different definitions in order to attain a more thorough understanding of RTW rates in the 2 populations.

Wage replacement benefits status was used as a surrogate measure of RTW for injury claimants. Total Temporary Disability Benefits (TD01) are granted to injured workers who are unable to work in any capacity and are receiving full wage replacement benefits. The max insurable earnings (MIE) provided by the WCB-Alberta in 2010 when this data was collected was 77000 dollars [38]. Partial Temporary Disability Benefits (TD02) are granted to injured workers who are able to work in a modified capacity and are receiving partial wage replacement benefits.
The measures of wage replacement benefits status investigated included TD01 and TD02 status at a time of clinical RTW assessment and 90 days after assessment as well as recurrence of these benefits. Recurrence was used for identifying claimants who were on wage replacement benefits at the time of their assessment, recovered and had benefits suspended, but then were placed back on their original wage replacement benefits within 90 days. While RTW and stoppage of disability benefits payments may be used as surrogate measures of recovery, it is important to be cognizant of the fact that these measures are not necessarily synonymous with physical recovery.

\section{Analysis}

Descriptive statistics were computed for all variables to characterize both the overall study population and urban and rural claimants separately. Three separate groups of variables were analyzed and compared between urban and rural claimants: 1) demographic and occupational characteristics; 2) health, injury, and clinical characteristics; and 3) wage replacement benefits. For continuous variables, the analysis of variance was used for determining statistical significance. For categorical variables, a $\mathrm{Chi}^{2}$ test was used. Multiple logistic regression models were created to: identify the relationship of urban/rural residence with multiple measures of RTW in order to best explain the association in Albertan workers with MSK injuries and compare the adjusted and unadjusted associations of urban/rural residence with the various measures of RTW to identify to what degree the associations were attenuated while controlling for other demographic, occupational, and health variables. Initially, univariate logistic regression was used for identifying the relationship between each factor with the various dichotomous outcome measures.

Next multivariable logistic regression models were created to determine the adjusted association between urban/rural residence while controlling for the effects of other factors. Criteria for inclusion in the models were that the variables 
had to be consistently significant at the $p=0.25$ level in the univariate analysis across multiple outcome measures, or were important descriptive variables in the population (age, sex). We tested the potential confounding effect of other variables by adding them to the final multivariable regression models. They were kept in the model if they changed the urban/rural regression coefficient by $10 \%$ or more.

This risk-factor modeling strategy allowed us to assess to what degree the effect of geographic location of residence was attenuated when compared to its univariate association. Since our goal was not to best explain variance in the outcome parsimoniously, but to descriptively illustrate the adjusted and non-adjusted associations across multiple variables, a consistent subset of variables was controlled to best demonstrate what effect urban/rural status had on several RTW measures. It was important to control the same subset of variables in order to reach a degree of comparability across models. The level of significance was set at $\alpha=0.05$. All statistical analyses were performed using IBM SPSS v. 21 (Chicago, USA).

\section{RESULTS}

A total of 7843 claimants were included in this study and out of this number, 5946 (70.1\%) were urban claimants and 2347 (29.9\%) were rural claimants. The Table 1 illustrates the demographic and occupational characteristics of the study population, as well as a comparative breakdown of the urban and rural populations. Rural and urban claimant populations did not differ significantly by age or sex although rural claimants tended to be older. Out of the 7843 claimants, $10.3 \%$ ( $\mathrm{N}=804)$ had missing data on the self-report PDI or Pain VAS questionnaires. There was a significant difference in the percentage of urban and rural claimants that had missing PDI or Pain VAS data ( $p=0.008$ ), with $25.9 \%$ of the population missing data being rural compared to $30.4 \%$ of the population not missing data being rural.

Thus, urban claimants were more likely than their rural counterparts to have missing PDI or Pain VAS data. This could potentially be due to a greater percentage of urban claimants requiring a translator, and therefore being less able to read and understand English.

The urban and rural claimant groups, however did differ statistically across other factors. While $12.8 \%$ of urban claimants' education level was less than a high school diploma and $6.2 \%$ had acquired a university degree, $15.3 \%$ of rural claimants did not have a high school diploma and $2.4 \%$ had a university degree ( $p<0.001)$. Rural claimants were more likely to be working in a blue-collar field (59.4\% vs. $55 \%, \mathrm{p}<0.001)$, and not to have modified work

Table 1. Demographic and occupational characteristics of urban and rural workers with work-related musculoskeletal injuries, Alberta, Canada, 2009-2011

\begin{tabular}{lcccc}
\hline \multirow{2}{*}{ Variable } & \multicolumn{3}{c}{ Injured workers } & $\mathrm{p}$ \\
\cline { 2 - 3 } & total & urban & rural & \\
\hline Respondents [n $(\%)]$ & $7843(100.0)$ & $5946(70.1)$ & $2347(29.9)$ & \\
Age [years] $(\mathrm{M} \pm \mathrm{SD})$ & $42.68 \pm 11.90$ & $42.54 \pm 11.88$ & $43.02 \pm 11.94$ & 0.10 \\
Gender [n $(\%)]$ & & & & 0.32 \\
$\quad$ male & $5014(63.9)$ & $3494(63.6)$ & $1520(64.8)$ & \\
$\quad$ female & $2829(36.1)$ & $2002(36.4)$ & $827(35.2)$ & \\
Job attached at admission [n(\%)] & & & & 0.03 \\
$\quad$ yes & $6671(85.1)$ & $4706(85.6)$ & $1965(83.7)$ & \\
$\quad$ no & $1172(14.9)$ & $790(14.4)$ & $382(16.3)$ & \\
\hline
\end{tabular}


Table 1. Demographic and occupational characteristics of urban and rural workers with work-related musculoskeletal injuries, Alberta, Canada, 2009-2011 - cont.

\begin{tabular}{|c|c|c|c|c|}
\hline \multirow{2}{*}{ Variable } & \multicolumn{3}{|c|}{ Injured workers } & \multirow{2}{*}{$\mathrm{p}$} \\
\hline & total & urban & rural & \\
\hline Interpreter required $[\mathrm{n}(\%)]$ & & & & $<0.001$ \\
\hline yes & $235(3.0)$ & $225(4.1)$ & $10(0.4)$ & \\
\hline no & $7608(97.0)$ & $5271(95.9)$ & $2337(99.6)$ & \\
\hline Education [n (\%)] & & & & $<0.001$ \\
\hline less than high school diploma & $1066(13.6)$ & $706(12.8)$ & $360(15.3)$ & reference \\
\hline high school diploma & $1351(17.2)$ & $919(16.7)$ & $432(18.4)$ & 0.35 \\
\hline partial technical school or university & $595(7.6)$ & $428(7.8)$ & $167(7.1)$ & 0.02 \\
\hline technical diploma & $1007(12.8)$ & $685(12.5)$ & $322(13.7)$ & 0.39 \\
\hline university degree & $398(5.1)$ & $341(6.2)$ & $57(2.4)$ & $<0.001$ \\
\hline not specified & $3426(43.7)$ & $2417(44.0)$ & $1009(43.0)$ & 0.01 \\
\hline Marital status [n (\%)] & & & & 0.001 \\
\hline single & $1332(17.0)$ & $965(17.6)$ & $367(15.6)$ & reference \\
\hline separated or divorced & $515(6.6)$ & $374(6.8)$ & $142(6.1)$ & 0.99 \\
\hline married, common-law, or widowed & $3021(38.5)$ & $2038(37.1)$ & $983(41.9)$ & 0.001 \\
\hline not-specified & $2974(37.9)$ & $2119(38.6)$ & $855(36.4)$ & 0.42 \\
\hline Type of work $[\mathrm{n}(\%)]$ & & & & 0.001 \\
\hline white-collar & $2784(35.5)$ & $2021(36.8)$ & $763(32.5)$ & reference \\
\hline blue-collar & $4419(56.3)$ & $3025(55.0)$ & $1394(59.4)$ & $<0.001$ \\
\hline health care field & $40(8.2)$ & $450(8.2)$ & $190(8.1)$ & 0.25 \\
\hline Working at time of assessment $[\mathrm{n}(\%)]$ & & & & 0.003 \\
\hline yes & $3637(46.4)$ & $2618(47.6)$ & $1019(43.4)$ & 0.001 \\
\hline no & $4189(53.4)$ & $2866(52.1)$ & $1323(56.4)$ & reference \\
\hline unknown & $17(0.2)$ & $12(0.2)$ & $5(0.2)$ & 0.85 \\
\hline Modified work available [n (\%)] & & & & $<0.001$ \\
\hline no & $3092(39.4)$ & $2078(37.8)$ & $1014(43.2)$ & reference \\
\hline yes-full time & $3801(48.5)$ & $2751(50.1)$ & $1050(44.7)$ & $<0.001$ \\
\hline yes-part time & $516(6.6)$ & $372(6.8)$ & $144(6.1)$ & 0.03 \\
\hline unknown & $434(5.5)$ & $295(5.4)$ & $139(5.9)$ & 0.75 \\
\hline Total annual earnings prior to injury $[\mathrm{n}(\%)]$ & & & & 0.05 \\
\hline$<25000$ dollars & $1979(25.2)$ & $1365(24.8)$ & $614(26.2)$ & 0.37 \\
\hline 25 000-77 000 dollars & $5130(65.4)$ & $3638(66.2)$ & $1492(63.6)$ & 0.04 \\
\hline > 77000 dollars & $734(9.4)$ & $493(9.0)$ & $241(10.3)$ & reference \\
\hline
\end{tabular}

M - mean; SD - standard deviation. 
available (43.2\% vs. $37.8 \%, \mathrm{p}<0.001)$. They were also more likely to have earned less than 25000 dollars during the year prior to their injury (26.2\% vs. $24.8 \%, \mathrm{p}=0.05)$, and to either be married, common-law, or widowed $(41.9 \%$ vs. $37.1 \%$, p < 0.001). However, urban claimants were more likely to require an interpreter $(4.1 \%$ vs. $0.4 \%, \mathrm{p}<0.001)$, to be job attached upon admission to a RTW program $(85.6 \%$ vs. $83.7 \%, p=0.03)$, and to be working at the time of their assessment $47.6 \%$ vs. $43.4 \%, p=0.003$ ).

The Table 2 illustrates the health, injury, and clinical characteristics of the total study population, as well as a comparative analysis of the urban and rural populations. While most of the measures achieved statistical significance due to the large sample size, some of the more notable differences include the number of days from accident to admission, the presence of comorbidities, the frequency of lower back injuries, the frequency of dislocation injuries, and the type of rehabilitation prescribed. Rural claimants on average had 242 days between the day of their accident and the day of their admission to a rehabilitation program, compared to 197 days for urban claimants ( $\mathrm{p}<0.001$ ). They were also more likely to have a diagnosed comorbidity, with $33.1 \%$ having at least one comorbidity compared to $27.3 \%$ of urban claimants ( $p<0.001)$, more likely to suffer a dislocation injury ( $2.9 \%$ vs. $1.9 \%, p=0.02)$, more likely to suffer a lower back injury $10 \%$ vs. $8.1 \%$, and more likely not to be enrolled in a rehabilitation program after their RTW assessment (22.4\% vs. $16.8 \%$, p < 0.001$)$.

The Table 3 illustrates the proportion of urban and rural claimants that were receiving the various types of disability

Table 2. Health, injury and clinical characteristics of urban and rural workers with work-related musculoskeletal injuries, Alberta, Canada, 2009-2011

\begin{tabular}{|c|c|c|c|c|}
\hline \multirow[b]{2}{*}{ Variable } & \multicolumn{3}{|c|}{ Injured workers } & \multirow[b]{2}{*}{$\mathrm{p}$} \\
\hline & $\begin{array}{c}\text { total } \\
(\mathrm{N}=7843)\end{array}$ & $\begin{array}{c}\text { urban } \\
(\mathrm{N}=5946)\end{array}$ & $\begin{array}{c}\text { rural } \\
(\mathrm{N}=2347)\end{array}$ & \\
\hline $\begin{array}{l}\text { Time from accident to RTW assessment } \\
\text { admission [days] }(\mathrm{M} \pm \mathrm{SD})\end{array}$ & $210.14 \pm 421.04$ & $196.53 \pm 402.06$ & $242.00 \pm 460.96$ & $<0.001$ \\
\hline $\begin{array}{l}\text { Time from accident to RTW assessment } \\
\text { admission [months] }(\mathrm{M} \pm \mathrm{SD})\end{array}$ & $7.00 \pm 14.03$ & $6.55 \pm 13.40$ & $8.07 \pm 15.37$ & $<0.001$ \\
\hline Previous claims $[\mathrm{n}](\mathrm{M} \pm \mathrm{SD})$ & $4.17 \pm 5.25$ & $4.07 \pm 5.24$ & $4.40 \pm 5.26$ & 0.01 \\
\hline Diagnosis group [n $(\%)]$ & & & & 0.02 \\
\hline fractures & 909 (11.6) & $622(11.3)$ & 287 (12.2) & reference \\
\hline dislocations & $172(2.2)$ & $104(1.9)$ & $268(2.9)$ & 0.04 \\
\hline sprains/strains & $3538(45.1)$ & $2484(45.2)$ & $1054(44.9)$ & 0.30 \\
\hline lacerations & $198(2.5)$ & $145(2.6)$ & $53(2.3)$ & 0.19 \\
\hline contusions & $374(4.8)$ & $285(5.2)$ & $89(3.8)$ & 0.006 \\
\hline nerve damage & $101(1.3)$ & $72(1.3)$ & $29(1.2)$ & 0.56 \\
\hline joint disorders & $2266(28.9)$ & $1586(28.9)$ & $680(29.0)$ & 0.39 \\
\hline other & $285(3.6)$ & $198(3.6)$ & $87(3.7)$ & 0.74 \\
\hline Anatomical site $[\mathrm{n}(\%)]$ & & & & 0.003 \\
\hline neck & 894 (11.4) & $660(12.0)$ & $234(10.0)$ & reference \\
\hline upper back & $77(1.0)$ & $64(1.2)$ & $13(0.6)$ & 0.08 \\
\hline lower back & $681(8.7)$ & $447(8.1)$ & $234(10.0)$ & $<0.001$ \\
\hline
\end{tabular}


Table 2. Health, injury and clinical characteristics of urban and rural workers with work-related musculoskeletal injuries, Alberta, Canada, 2009-2011 - cont.

\begin{tabular}{|c|c|c|c|c|}
\hline \multirow[b]{2}{*}{ Variable } & \multicolumn{3}{|c|}{ Injured workers } & \multirow[b]{2}{*}{$\mathrm{p}$} \\
\hline & $\begin{array}{c}\text { total } \\
(\mathrm{N}=7843)\end{array}$ & $\begin{array}{c}\text { urban } \\
(\mathrm{N}=5946)\end{array}$ & $\begin{array}{c}\text { rural } \\
(\mathrm{N}=2347)\end{array}$ & \\
\hline Anatomical site $[\mathrm{n}(\%)]$ - cont. & & & & 0.003 \\
\hline other torso & $628(8.0)$ & $445(8.1)$ & $183(7.8)$ & 0.20 \\
\hline upper extremity & $3036(38.7)$ & $2105(38.3)$ & $931(39.7)$ & 0.01 \\
\hline lower extremity & $1603(20.4)$ & $1110(20.2)$ & $493(21.0)$ & 0.02 \\
\hline multiple site & $24(0.3)$ & $17(0.3)$ & $7(0.3)$ & 0.74 \\
\hline not specified & $896(11.4)$ & $645(11.7)$ & $251(10.7)$ & 0.38 \\
\hline Comorbidity $[\mathrm{n}(\%)]$ & & & & $<0.001$ \\
\hline yes & $2275(29.0)$ & $1498(27.3)$ & $777(33.1)$ & \\
\hline no & $5568(71.0)$ & $3998(72.7)$ & $1570(66.9)$ & \\
\hline Doctor visits [n] (MะSD) & $14.53 \pm 19.45$ & $13.92 \pm 18.66$ & $15.96 \pm 21.12$ & $<0.001$ \\
\hline Physiotherapy visits [n] $(\mathrm{M} \pm \mathrm{SD})$ & $19.06 \pm 24.53$ & $19.47 \pm 25.02$ & $18.11 \pm 23.32$ & 0.03 \\
\hline Chiropractor visits $[\mathrm{n}](\mathrm{M} \pm \mathrm{SD})$ & $1.02 \pm 4.31$ & $1.06 \pm 4.48$ & $0.94 \pm 3.90$ & 0.27 \\
\hline Rehabilitation program undertaken $[\mathrm{n}(\%)]$ & & & & $<0.001$ \\
\hline no rehabilitation & $1448(18.5)$ & $923(16.8)$ & $525(22.4)$ & reference \\
\hline single service community physical therapy & $1182(15.1)$ & $768(14.0)$ & $414(17.6)$ & 0.51 \\
\hline complex RTWS & $266(3.4)$ & $180(3.3)$ & $86(3.7)$ & 0.22 \\
\hline provider-based RTWS & $4070(51.9)$ & $2970(54.0)$ & $1100(46.9)$ & $<0.001$ \\
\hline work site-based RTWS & $121(1.5)$ & $71(1.3)$ & $50(2.1)$ & 0.27 \\
\hline hybrid & $756(9.6)$ & $584(10.6)$ & $172(7.3)$ & $<0.001$ \\
\hline \multicolumn{5}{|l|}{ SF-36 scores $(\mathrm{M} \pm \mathrm{SD})$} \\
\hline physical functioning & $54.39 \pm 25.08$ & $54.00 \pm 25.16$ & $55.25 \pm 24.89$ & 0.06 \\
\hline physical role & $30.54 \pm 26.25$ & $30.60 \pm 26.22$ & $30.40 \pm 26.31$ & 0.78 \\
\hline pain index & $26.49 \pm 20.66$ & $26.27 \pm 20.86$ & $26.98 \pm 20.19$ & 0.19 \\
\hline general health perceptions & $66.96 \pm 19.47$ & $66.26 \pm 19.61$ & $68.53 \pm 19.08$ & $<0.001$ \\
\hline vitality & $49.14 \pm 20.97$ & $48.74 \pm 20.93$ & $50.06 \pm 21.04$ & 0.02 \\
\hline emotional role & $57.45 \pm 33.15$ & $56.47 \pm 33.10$ & $59.65 \pm 33.18$ & $<0.001$ \\
\hline mental health index & $62.52 \pm 21.23$ & $61.54 \pm 21.34$ & $64.72 \pm 20.83$ & $<0.001$ \\
\hline social functioning & $52.85 \pm 27.33$ & $52.25 \pm 27.35$ & $54.19 \pm 27.25$ & 0.01 \\
\hline Total PDI percentage score $(\mathrm{M} \pm \mathrm{SD})$ & $47.26 \pm 22.25$ & $47.60 \pm 22.37$ & $46.49 \pm 21.96$ & 0.05 \\
\hline Pain VAS score $(\mathrm{M} \pm \mathrm{SD})$ & $5.08 \pm 2.56$ & $5.14 \pm 2.54$ & $4.96 \pm 2.58$ & 0.01 \\
\hline
\end{tabular}

* $205(2.61 \%)$ of claimants had 0 doctor visits.

** 1837 (23.4\%) of claimants had 0 physiotherapy visits.

*** $7246(92.4 \%)$ of claimants had 0 chiropractor visits.

RTWS - return to work services; SF-36 - Short Form 36 Health Survey; PDI - Pain Disability Index; VAS - Pain Visual Analog Scale.

Other abbreviations as in Table 1. 
Table 3. Wage replacement benefits in urban and rural workers with work-related musculoskeletal injuries, Alberta, Canada, 2009-2011

\begin{tabular}{|c|c|c|c|c|}
\hline \multirow{2}{*}{ Variable } & \multicolumn{3}{|c|}{$\begin{array}{l}\text { Injured workers } \\
{[\mathrm{n}(\%)]}\end{array}$} & \multirow{2}{*}{$\mathrm{p}$} \\
\hline & $\begin{array}{c}\text { total } \\
(\mathrm{N}=7843)\end{array}$ & $\begin{array}{c}\text { urban } \\
(\mathrm{N}=5946)\end{array}$ & $\begin{array}{c}\text { rural } \\
(\mathrm{N}=2347)\end{array}$ & \\
\hline $\begin{array}{l}\text { Receiving total disability benefits at discharge } \\
\text { from assessment }\end{array}$ & & & & 0.002 \\
\hline yes & $3237(41.3)$ & $2206(40.1)$ & $1031(43.9)$ & \\
\hline no & $4606(58.7)$ & $3290(59.9)$ & $1316(56.1)$ & \\
\hline $\begin{array}{l}\text { Receiving total disability benefits } 90 \text { days after } \\
\text { discharge from assessment }\end{array}$ & & & & $<0.001$ \\
\hline yes & $499(6.4)$ & $311(5.7)$ & $188(8.0)$ & \\
\hline no & 7344 (93.6) & $5185(94.3)$ & $2159(92.0)$ & \\
\hline $\begin{array}{l}\text { Receiving partial disability benefits } \\
\text { at discharge from assessment }\end{array}$ & & & & 0.005 \\
\hline yes & 1265 (16.1) & $928(16.9)$ & 337 (14.4) & \\
\hline no & 6578 (83.9) & $4568(83.1)$ & 2010 (85.6) & \\
\hline $\begin{array}{l}\text { Receiving partial disability benefits } 90 \text { days } \\
\text { after discharge from assessment }\end{array}$ & & & & 0.77 \\
\hline yes & $332(4.2)$ & $235(4.3)$ & $97(4.1)$ & \\
\hline no & $7511(95.8)$ & $5261(95.7)$ & 2250 (95.9) & \\
\hline $\begin{array}{l}\text { Recurrence of total disability benefits } \\
\text { within } 90 \text { days* }\end{array}$ & & & & 0.04 \\
\hline yes & $83(2.6)$ & $48(2.2)$ & $35(3.4)$ & \\
\hline no & 3154 (97.4) & $2158(97.8)$ & $996(96.6)$ & \\
\hline $\begin{array}{l}\text { Recurrence of partial disability benefits } \\
\text { within } 90 \text { days** }\end{array}$ & & & & 0.21 \\
\hline yes & $16(1.4)$ & $14(1.6)$ & $2(0.7)$ & \\
\hline no & 1160 (98.6) & 855 (98.4) & 305 (99.3) & \\
\hline
\end{tabular}

* Claimants on full disability benefits at discharge from assessment only.

** Claimants on partial disability benefits at discharge from assessment only.

benefits. At the time of discharge from their RTW assessment, rural workplace injury claimants were more likely to be receiving TD01 full disability benefits compared to their urban counterparts ( $43.9 \%$ vs. $40.1 \%, \mathrm{p}=0.002)$. Conversely, a greater proportion of the urban claimant population was receiving TD02 partial disability benefits at the time of discharge from their RTW assessment $(16.9 \%$ vs. $14.4 \%, \mathrm{p}=0.005)$.
At 90 days post-assessment, a larger proportion of rural claimants were still receiving TD01 full disability benefits $(8 \%$ vs. $5.7 \%, \mathrm{p}<0.001)$, while a similar percentage of urban and rural claimants were receiving TD02 partial disability benefits 90 days post-assessment (4.3\% vs. $4.1 \%, p=0.77)$. Out of the claimants who were receiving TD01 benefits at discharge from their assessment and recovered, rural claimants were more likely to have 
a recurrence of receiving total disability benefits than their urban counterparts ( $3.4 \%$ vs. $2.2 \%, p=0.04)$. Conversely, in assessing recurrence of TD02 benefits, there was no significant difference between urban and rural claimants ( $1.6 \%$ vs. $0.7 \%, \mathrm{p}=0.21$ ).

Comparison of RTW outcomes between urban and rural claimant groups using the logistic regression analysis is shown in the Table 4. The crude analysis of different claimant population samples indicated rural workers to be 1.45 (1.20-1.75) and 1.48 (1.18-1.85) times the odds more likely to be receiving TD01 full disability benefits 90 days after their RTW assessment when compared to their urban counterparts. Conversely, while rural claimants were 0.74 (0.51$1.07)$ and $0.68(0.43-1.07)$ times the odds less likely to be receiving TD02 partial disability benefits at 90 days, it was not to a statistically significant degree. When the effects of other factors were controlled for, the associations only changed minutely and rural workers were still 1.39 (1.13-1.71) or 1.43 (1.12-1.84) times the odds more likely to be receiving TD01 full disability benefits at 90 days.
Similarly, the association between rural residence and TD02 partial disability benefits at 90 days hardly changed and remained statistically insignificant at 0.75 $(0.50-1.11)$ or $0.63(0.38-1.05)$. Furthermore, not only were rural workers more likely to be receiving full disability benefits 90 days after their assessment, but rural claimants were $1.58(1.20-2.46)$ times the odds more likely than urban claimants to go back on full disability benefits within the 90 day time frame. This association slightly increased to 1.68 (1.06-2.67) when controlling for the effects of other factors. Inclusion of the Pain VAS and PDI variables in the regression analyses significantly reduced the population sample sizes due to many claimants failing to fill out these questionnaires. However, including them did not alter any of the multivariate regression models to a meaningful or statistically significant degree $(<10 \%$ change).

\section{DISCUSSION}

Our findings indicate that the rural Albertan population is at greater risk of prolonged work absence as indicated

Table 4. Relationship between rural residence and measures of return to work (RTW) in workers with work-related musculoskeletal injuries, Alberta, Canada, 2009-2011

\begin{tabular}{lcc}
\hline \multicolumn{1}{c}{ Claimant inclusion criteria } & Crude OR (95\% CI) & Adjusted* OR (95\% CI) \\
\hline $\begin{array}{l}\text { Receiving total disability benefits } 90 \text { days after discharge from assessment } \\
\text { all claimants }(\mathrm{N}=7843)\end{array}$ & $1.45(1.20-1.75)$ & $1.39(1.13-1.71)$ \\
TD01 at day $0(\mathrm{~N}=3237)$ & $1.48(1.18-1.85)$ & $1.43(1.12-1.84)$ \\
$\begin{array}{l}\text { Receiving partial disability benefits } 90 \text { days after discharge from assessment } \\
\text { all claimants, excluding TD01 at day } 0(\mathrm{~N}=4 \text { 606) }\end{array}$ & $0.74(0.51-1.07)$ & $0.75(0.50-1.11)$ \\
TD02 at day $0(\mathrm{~N}=1261)$ & $0.68(0.43-1.07)$ & $0.63(0.38-1.05)$ \\
Recurrence of total disability benefits within 90 days & $1.58(1.02-2.46)$ & $1.68(1.06-2.67)$ \\
$\quad$ TD01 at day $0(\mathrm{~N}=3237)$ & & \\
Recurrence of partial disability benefits within 90 days & insufficient sample size for these analyses \\
TD02 at day $0(\mathrm{~N}=1261)$ & &
\end{tabular}

TD01 - Total Temporary Disability Benefits; TD02 - Partial Temporary Disability Benefits.

OR - odds ratio; $\mathrm{CI}$ - confidence interval.

* Variables included in all adjusted models: urban/rural, age, gender, diagnosis group/type of injury, rehabilitation program, income, education level, type of work, number of months accident to admission, number of doctor visits, number of physiotherapy visits, admission job attached, modified work available. 
by higher likelihood of receiving total temporary disability benefits and recurrence of benefits. The urban population was more likely to be receiving partial disability benefits for their injuries, although not to a statistically significant degree. Unexpectedly, after controlling for demographic, occupational, and health factors, the relationship between geographic location of residence and recovery from MSK injury, using RTW and stoppage of disability benefits as an indicator of recovery, was not attenuated to any meaningful degree in any of our measures of RTW. These findings indicate either that there is something intrinsically different between urban and rural populations that accounts for the worse outcomes or, more likely, that the variables that do explain the differences in RTW between these 2 populations were not analyzed or controlled for in this study. Most likely other unmeasured factors explain the association between geographic location and RTW and should be identified by future, more controlled and directed research.

Consistently with our findings, a review of previous research on this topic demonstrated that compared to urban populations, rural populations tend to be at greater risk of prolonged work absence and poorer recovery outcomes $[26,27,39,40]$. In a systematic review investigating work disability and health of rural and urban healthcare workers, it was found that rural healthcare workers had higher rates of occupational injury and were at greater risk for prolonged work absence [37]. Similarly, investigation of 149110 disability claims for workplace injury from 2002-2008 in the state of Washington showed individuals living in small towns and isolated rural areas were on long-term disability for a greater period of time than individuals living in the urban core [26]. Like our study, the association remained after controlling for the nature of the injury, socio-demographic factors, and employment and administrative claim characteristics.

Although not exclusively examining workplace injuries, two other studies nonetheless providevaluable insights. The analysis of people suffering from chronic low back pain in North Carolina suggested rural residents had the greatest functional loss [27], while a study of 34933 trauma patients in the American National Trauma Data Bank from 2001-2005 concluded that people who suffered their injury at a rural site had worse functional outcomes at hospital discharge when compared to people who suffered their injury at rural sites [40].

Conversely, one high quality study found less work disability in claimants with higher rurality scores. In research based in the USA, Young et al. [28] devised a rurality classification system that was calculated using census data. The classification took the number of people living in a rural area of a region divided by the total population of that region, and then multiplying this value by 100 . This classification is different from our definition of greater than 50000 inhabitants representing an urban centre. Similar to our findings, however, the association found was not attenuated after controlling for the effects of other factors, including age, sex, body part injured, and occupation [28].

While other research provides valuable insights into the association between geographic location of residence and RTW or functional recovery, it is important to realize that due to the multitude of socio-economic, political, and demographic differences and complexities between unique populations, it is difficult to generalize findings across jurisdictions or areas. Thus, this further highlights the need for more provincial and state-specific research in the field in order to better understand workplace injuries and how rural workers may be best supported to RTW in a timely manner.

The 2011 Canadian Census identified that $19.4 \%$ of the Albertan population, or 707646 people, resided in rural areas or small towns, exceeding the statistic of $18 \%$ for the Canadian population as a whole [25]. However, 29.9\% of workers' compensation claimants in this study resided in a rural community. These differences may possibly be attributed in part to different definitions of "rural" being used by the WCB in our study compared to Census 
Canada data. In their data, the WCB defined communities with populations less than 50000 as rural, whereas the Statistics Canada classification system defined Rural and Small Town (RST) communities as areas with populations less than 10000 where less than $50 \%$ of employed individuals commute to a Census Metropolitan Area (CMA) or a Census Agglomeration (CA) [25,30].

However, the difference in the proportion of the population being rural may also be explained in part by the workers' compensation claimant population not being representative of the greater population, as our research suggests rural workers are more likely to remain on disability benefits for an extended period of time. It may also suggest rural workers are at increased risk of injury.

Comparison of our study population with the greater Canadian population provides several insights. While our injured worker population from rural areas had a lower level of formal education, consistent with findings from the 2011 Canadian Census, some differences were noted. Rural and small town Canadian populations have been consistently found to be older and have a greater proportion of seniors than urban populations. The 2011 census was no exception, with rural and small town populations having a median age of 42.1 years while urban populations had a median age of 38.9 years [29].

However, there was no statistically significant difference between the ages of the 2 populations in our study. Also, while census data showed rural and small town populations to be of lower socio-economic status than their urban counterparts [30], an interesting dichotomy was found in our population of injured workers. Prior to their injury, a slightly greater proportion of rural claimants had made $<25000$ dollars that year, but a greater proportion also made $>77000$ dollars. Thus, more urban claimants earned between 25 000-77 000 dollars.

These contrasting findings could be due to differences between the working population and the population as a whole, as although there are more elderly people in rural areas, many of them may no longer be working or eligible for compensation claims (such as farmers). Additionally, the economy in Alberta draws many young workers from across Canada, and this is illustrated in the median age of Alberta's inhabitants being 36.5 years old vs. 40.6 years old for all of Canada in 2011 [25]. With much of the heavy industry that was attracting young workers in Alberta during the period of our study being in rural areas, this would further skew the normal age distribution of the population. The greater than expected pre-injury earnings in rural claimants is also likely attributable to the high earning opportunities due to the booming Alberta economy in 2010-2011. Although this study utilized a large, population-based database that has been previously used for research and includes a wide range of demographic, occupational, and health variables [31,34], some limitations were also present. As this study was a secondary analysis, the research team did not collect the data and as such had no control of what variables were collected or the quality of the data. Missing or unspecified data was also a limitation that should be taken into consideration, as some of the variables (e.g., level of education) were lacking data for a significant proportion of the population, and urban claimants were more likely than their rural counterparts to not respond to the PDI or Pain VAS questionnaires.

Furthermore, the database only included injured workers who failed to initially RTW after their injury and submitted a workplace injury claim that was accepted by WCBAlberta. Thus, it is not representative of all workers in Alberta suffering from a musculoskeletal injury. Lastly, using RTW as a surrogate measure of recovery also introduces other limitations as it should not be assumed that RTW is synonymous with greater physical/functional recovery after an injury, as there are a multitude of other socio-demographic and occupational/employment that need to be taken into account as well. 


\section{CONCLUSIONS}

In conclusion, when compared to their urban counterparts, rural Albertan MSK injury claimants appeared to have lower levels of formal education, were more likely to be employed in a blue-collar profession, have diagnosed comorbidity, have no modified work opportunities available, and were not referred for rehabilitation. Rural claimants are also more likely to be receiving wage replacement benefits and be at risk of delayed recovery and recurrence of disability benefits. Controlling for the effects of multiple demographic, occupational, and health factors did not attenuate observed associations, and further research is required to better understand why rural workers are more likely to experience longer episodes of work disability than their urban counterparts and, furthermore, if these statistically significant findings do also carry clinical significance for injured rural workers receiving disability benefits in Alberta.

\section{ACKNOWLEDGMENTS}

The Workers' Compensation Board of Alberta provided the data for this research and funded the original study from which data was obtained.

\section{REFERENCES}

1. Leigh JP. Economic burden of occupational injury and illness in the United States. Milbank Q. 2011;89(4):728-72, https:// doi.org/10.1111/j.1468-0009.2011.00648.x.

2. Lane R, Desjardins S. Population and public health branch of Canada. Strategic policy directorate. Policy research division. Economic burden of illness in Canada [ebook]. Ottawa: Health Canada; 2002.

3. Wilkins K, Mackenzie S. Work injuries. Health Rep [Internet]. 2007 [cited 2016 Jan 8];18(3):1. Available from: http:// citeseerx.ist.psu.edu/viewdoc/download?doi=10.1.1.616.5623 $\&$ rep $=$ rep $1 \&$ type $=$ pdf.

4. Statistics Canada. Billette J, Janz T [Internet]. Ottawa: The Statistics; 2010 [updated 2015 Nov 27; cited 2016 Jan 8].
Injuries in Canada: Insights from the Canadian Community Health Survey. Available from: http://www.statcan.gc.ca/ pub/82-624-x/2011001/article/11506-eng.htm.

5. Workers' Compensation Board of Alberta. Workers' Compensation Board - Alberta 2012 Annual Report [Internet]. Edmonton: The Board; 2012 [cited 2016 Jan 8]. Available from: http://www.wcb.ab.ca/pdfs/public/annual_report_ 2012.pdf.

6. Alberta Human Services. Occupational injuries and diseases in Alberta: Lost-time claims, disabling injury claims, and claim rates. 2011 Summary [Internet]. Edmonton: The Services; 2012 [cited 2016 Jan 8]. Available from: http://work. alberta.ca/documents/2011-Occupational-Injuries-DiseasesAlberta-Summary.pdf.

7. Association of the Workers' Compensation Boards of Canada [Internet]. Toronto: The Boards; 2012 [cited 2016 Jan 8]. Accepted time-loss injuries by jurisdiction: 2012 Statistics. Available from: http://awcbc.org/?page_id=14\#injuries.

8. Seland K, Cherry N, Beach J. A study of factors influencing return to work after wrist or ankle fractures. Am J Ind Med. 2006;49(3):197-203, https://doi.org/10.1002/ajim.20258.

9. Hou W, Liang H, Sheu C, Hsieh C, Chuang H. Return to work and quality of life in workers with traumatic limb injuries: A 2-year repeated-measurements study. Arch Phys Med Rehabil. 2013;94(4):703-10, https://doi.org/10.1016/ j.apmr.2012.10.033.

10. MacKenzie EJ, Bose MJ, Kellam JF, Pollak AN, Webb LX, Swiontkowski MF, et al. Early predictors of long-term work disability after major limb trauma. J Trauma. 2006;61(3): 688-94, https://doi.org/10.1097/01.ta.0000195985.56153.68.

11. Cheng A, Hung L. Socio-demographic predictors of work disability after occupational injuries. Hong Kong J Occup Ther. 2007;17(2):45-53, https://doi.org/10.1016/S1569-1861 (08)70003-2.

12. Van der Giezen A, Bouter L, Nijhuis F. Prediction of returnto-work of low back pain patients sicklisted for 3-4 months. Pain. 2000;87(3):285-94, https://doi.org/10.1016/S0304-3959 (00)00292-X. 
13. Clay F, Newstead S, McClure R. A systematic review of early prognostic factors for return to work following acute orthopaedic trauma. Injury. 2010;41(8):787-803, https://doi. org/10.1016/j.injury.2010.04.005.

14. Hildebrandt J, Pfingsten M, Saur P, Jansen J. Prediction of success from a multidisciplinary treatment program for chronic low back pain. Spine. 1997;22(9):990-1001, https:// doi.org/10.1097/00007632-199705010-00011.

15. Park S. Associations of demographic and injury-related factors with return to work among job-injured workers with disabilities in South Korea. J Rehabil Med. 2012;44(5):473-6, https://doi.org/10.2340/16501977-0907.

16. Vowles K, Gross R, Sorrell J. Predicting work status following interdisciplinary treatment for chronic pain. Eur J Pain. 2004;8(4):351-8, https://doi.org/10.1016/j.ejpain.20 03.10.009.

17. Burger H, Marinček Č. Return to work after lower limb amputation. Disabil Rehabil. 2007;29(17):1323-9, https:// doi.org/10.1080/09638280701320797.

18. Watson P, Booker C, Moores L, Main C. Returning the chronically unemployed with low back pain to employment. Eur J Pain. 2004;8(4):359-69, https://doi.org/10.1016/j.ej pain.2003.11.003.

19. Berecki-Gisolf J, Clay F, Collie A, McClure R. Predictors of sustained return to work after work-related injury or disease: Insights from workers' compensation claims records. J Occup Rehabil. 2012;22(3):283-91, https://doi.org/10.1007/ s10926-011-9344-y.

20. Breslin F, Tompa E, Zhao R, Pole JD, Amick III BC, Smith PM, et al. The relationship between job tenure and work disability absence among adults: A prospective study. Accid Anal Prev. 2008;40(1):368-75, https://doi.org/10.1016/ j.aap.2007.07.007.

21. Fan JK, McLeod CB, Koehoorn M. Sociodemographic, clinical, and work characteristics associated with returnto-work outcomes following surgery for work-related knee injury. Scand J Work Environ Health. 2010;36(4):332-8, https://doi.org/10.5271/sjweh.2901.
22. Clay F, Newstead S, Watson W, Ozanne-Smith J, McClure R. Bio-psychosocial determinants of time lost from work following non life threatening acute orthopaedic trauma. BMC Musculoskelet Disord. 2010;11:1-11, https://doi.org/ 10.1186/1471-2474-11-6.

23. Voaklander D, Beaulne A, Lessard R. Factors related to outcome following a work hardening program. J Occup Rehabil. 1995;5(2):71-85, https://doi.org/10.1007/BF0 2109911.

24. Hebert J, Ashworth N. Predictors of return to work following traumatic work-related lower extremity amputation. Disabil Rehabil. 2006;28(10):613-8, https://doi.org/10.1080/ 09638280500265219.

25. Statistics Canada [Internet]. Ottawa: The Statistics; 2011 [cited 2016 Jan 8]. Focus on geography series, 2011 Census: Province of Alberta. Available from: http://www12.statcan. gc.ca/census-recensement/2011/as-sa/fogs-spg/Facts-pr-eng. $\mathrm{cfm}$ ?Lang $=$ eng $\& \mathrm{GC}=48$.

26. Fan Z, Foley M, Rauser E, Bonauto D, Silverstein B. Effects of residential location and work-commuting on long-term work disability. J Occup Rehabil. 2013;23(4):610-20, https:// doi.org/10.1007/s10926-013-9424-2.

27. Goode A, Freburger J, Carey T. The influence of rural versus urban residence on utilization and receipt of care for chronic low back pain. J Rural Health. 2013;29(2):205-14, https:// doi.org/10.1111/j.1748-0361.2012.00436.x.

28. Yang AE, Wasiak R, Webster BS, Shayne RGF. Urban-rural differences in work disability after an occupational injury. Scan J Work Environ Health. 2008;34(2):158-64, https://doi. org $/ 10.5271 /$ sjweh.1217.

29. Community Information Database [Internet]. Canadian Rural Facts. c2011 [cited 2016 Jan 8]. Available from: http:// www.cid-bdc.ca/rural-facts.

30. Canadian Institute for Health Information. How healthy are rural Canadians? An assessment of their health status and health determinants [Internet]. Ottawa: The Institute; 2006 [cited 2016 Jan 8]. Available from: https://secure.cihi. ca/free_products/rural_canadians_2006_report_e.pdf. 
31. Gross D, Zhang J, Steenstra I, Barnsley S, Haws C, Amell T, et al. Development of a computer-based clinical decision support tool for selecting appropriate rehabilitation interventions for injured workers. J Occup Rehabil. 2013;23(4): 597-609, https://doi.org/10.1007/s10926-013-9430-4.

32. Workers' Compensation Board of Alberta. Assessment discharge data collection reference guide. Edmonton: WCB Health Care Services; 2005.

33. Workers' Compensation Board of Alberta. Program discharge data collection reference guide. Edmonton: WCB Health Care Services; 2009.

34. Algarni F, Gross D, Senthilselvan A, Battié M. Ageing workers with work-related musculoskeletal injuries. Occup Med. 2015;65(3):229-37, https://doi.org/10.1093/occmed/kqu213.

35. Stephens B, Gross D. The influence of a continuum of care model on the rehabilitation of compensation claimants with soft tissue disorders. Spine. 2007;32(25):2898-904, https:// doi.org/10.1097/BRS.0b013e31815b64b6.

36. Gross D, Battié M. Recovery expectations predict recovery in workers with back pain but not other musculoskeletal conditions. J Spinal Disord Tech. 2010;23(7):451-6, https:// doi.org/10.1097/BSD.0b013e3181d1e633.

37. Government of Canada [Internet]. Ottawa: The Government; 2011 [cited 2016 Jan 8]. National Occupational Classification. Available from: http://www5.hrsdc.gc.ca/NOC/ English/NOC/2011/OccupationIndex.aspx.

38. Workers' Compensation Board of Alberta. Maximum insurable earnings for 2010 [Internet]. Edmonton: The Board; 2010 [cited 2016 Jan 8]. Available from: http:// s3.amazonaws.com/zanran_storage/www.wcb.ab.ca/ContentPages/48392074.pdf.

39. Franche R, Murray E, Ostry A, Ratner P, Wagner S, Harder $\mathrm{H}$. Work disability prevention in rural areas: A focus on healthcare workers. Rural Remote Health. 2010 Oct [cited 2016 Jan 8];10(4):1-24. Available from: http://www.rrh.org. au/publishedarticles/article_print_1502.pdf.

40. Sihler K, Hemmila M. Injuries in nonurban areas are associated with increased disability at hospital discharge. J Trauma. 2009;67(5):903-9, https://doi.org/10.1097/TA.0b0 13e3181aebec2.

This work is available in Open Access model and licensed under a Creative Commons Attribution-NonCommercial 3.0 Poland License - http://creativecommons.org/ licenses/by-nc/3.0/pl/deed.en. 